\title{
ANALISA PERENCANAAN KAPASITAS PRODUKSI PADA PT. MUNCUL ABADI DENGAN METODE ROUGH CUT CAPACITY PLANNING
}

\author{
I k s a n \\ Jurusan Teknik Industri \\ Institut Teknologi Adhi Tama Surabaya \\ Email : xsn_faruq@yahoo.com
}

\begin{abstract}
$\mathrm{P}$ oduction capacity planning this company have obstacle in meeting its production target, then company oftentimes unable to fulfill consumer demands. It can be inflict the company loose. The problems is how planning production capacity based on Rough Cut Capacity Planning (RCCP) Method in order to make consumers demand be able to supplied? " The researcher attempt to resolving problem in PT Muncul Abadi by aiming calculate product capacity plan based on Rough Cut Capacity Planning Method and determine required product. To be useful as consideration for the company in planning production. Forecast done within the coming one year term. Capacity planning base on Rough Cut Capacity Planning (RCCP) Method.

From forecast result toward previous demand quantity period within 12 periods we could be make production index schedule and order Bill of Resources with standard time that is 0,000316 hours $/ \mathrm{kg}$. Able to know machine capacity need in 1 workday $=8$ hours day, with 3 shifts per day, 1 week $=6$ workdays, 1 month $=25$ effective workdays then : available time per month $=25$ effective workdays x 8 hours day x 3 shift per day $=600$ hours $/$ month. Available capacity for Washing machine $=1.394$ hours $/$ month. Available capacity for Crushing machine $=1.394$ hours $/$ month . Available capacity for Pelletizing machine $=1.859$ hours $/$ month .
\end{abstract}

Keywords : Planning, Capacity, Production, Method, Rough Cut Capacity Planning.

\section{PENDAHULUAN}

Keberhasilan dari perencanaan dan pengendalian manufacturingmembutuhkanperencanaankapasitas yang efektif agar dapat memenuhi jadwal produksi yang telah ditetapkan. Kekurangan kapasitas akan menyebabkan kegagalan dalam memenuhi terget produksi sehingga terjadi keterlambatan pengiriman ke pelanggan yang dapat menyebabkan perusahaan kehilangan kepercayaan yang mengakibatkan reputasi perusahaan akan menurun atau hilang sama sekali. Kelebihan kapasitas juga dapat mengakibatkan tingkat utilitas sumber-sumber daya yang rendah, biaya meningkat, harga produk menjadi tidak kompetitif, kehilangan pangsa pasar dan penurunan keuntungan. Dengan demikian kekurangan kapasitas maupun kelebihan kapasitas akan memberikan dampak negatif bagi system manufacturing, sehingga perencanaan kapasitas yang efektif adalah menyediakan kapasitas sesuai dengan kebutuhan pada waktu yang tepat.

PT Muncul Abadi merupakan salah satu industri manufacturing yang bergerak dalam bidang usaha daur ulang plastik, yang produksinya berupa Pellet atau yang biasa disebut dengan Biji Plastik. Produk Pelletyang dihasilkan oleh perusahaan iniada3 jenis, yaitu : Pellet jenis Polyprophylen (PP), Pellet jenis PP ini bahan bakunya berupa pembungkus sabun, deterjen, shampoo,dll. Pellet jenis Polyethylen (PE), Pellet jenis PE ini bahan bakunya berupa terpal dan plastik kresek. Pellet jenis High Density (HD), Pellet jenis HD ini bahan bakunya berupa kertas pembungkus tebal. Produk ini digunakan sebagai campuran pembuatan produk alat-alat rumah tangga yang terbuat dari plastik, tali raffia, bak,kursi plastik, dll. Pellet jenis Polyprophylen di perusahaan ini produk yang paling banyak di pesan oleh konsumen, sehingga dapat mendatangkan profit paling banyak untuk perusahaan, untuk itu produk Pellet jenis Polyprophylen ini dipilih sebagai obyek penelitian.

PT Muncul Abadi ini mempunyai karyawan produksi sebanyak 150 orang dan area pemasaran produk ini berada di dalam negeri, antara lain: PT Yanaprima Hasta Persada sidoarjo, Pasuruan, Malang, Surabaya, dll. Perusahaan ini pertama kali produksi pada tahun 1997 dan pada tahun 1999 
produk ini juga di eksport ke negara Cina dengan order produksinya di buat atas dasar "custumer

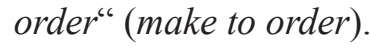

Perencanaan kapasitas produksi perusahaan ini mengalami kendala dalam memenuhi target produksinya, sehingga perusahaan sering kali tidak dapat memenuhi permintaan konsumen. Hal ini dapat merugikan perusahaan itu sendiri. Bagaimana merencanakan kapasitas produksi berdasarkan metode Rough Cut Capacity Planning (RCCP) agar permintaan para pelanggan dapat terpenuhi?"

\section{Tujuan Penelitian}

Menghitung rencana kapasitas produk berdasarkan metode Rough Cut Capacity Planning (RCCP) dan menentukan kapasitas produksi yang dibutuhkan.

Adapun manfaat dari penelitian ini sangat berguna Sebagai bahan pertimbangan bagi perusahaan dalam merencanakan produksi. Penelitian hanya dilakukan pada produk Pellet jenis Polyprophylen. Penelitian menggunakan data permintaan dan data produksi satu tahun. Peramalan dilakukan untuk jangka waktu satu tahun yang akan datang. Perencanaan kapasitas berdasarkan metode Rough Cut Capacity Planning (RCCP).

\section{Tinjauan Pustaka}

\section{Perencanaan Produksi}

Perencanaan produksi dilakukan dengan tujuan menentukan arah awal dari tindakan-tindakan yang harus dilakukan di masa mendatang, apa yang harus dilakukan, berapa banyak melakukannya dan kapan harus melakukan karena perencanaan ini berkaitan dengan masa mendatang, maka perencanaan disusun atas dasar perkiraan yang dibuat berdasarkan data masa lalu dengan menggunakan beberapa asumsi. Oleh karena itu perencanaan tidak akan selalu memberikan hasil sebagaimana yang diharapkan dalam rencana tersebut, sehingga setiap perencanaan yang dibuat harus dievaluasi secara berkala dengan jalan melakukan pengendalian.(Nasution,Arman Hakim.1999.hal 11)

Hasil perencanaan produksi adalah sebuah rencana kerja. Rencana kerja yang kita buat haruslah merupakan alternatif yang paling baik untuk mencapai tujuan yang telah ditetapkan secara efektif dan efisien. Karena akan menyebabkan faktor-faktor produksi yang kita gunakan berlebihan, oleh karena itu maka perencanaan tidak lain merupakan penentuan tujuan utama organisasi beserta upaya untuk mencapai tujuan tersebut. Kemudian untuk mempunyai tujuan tersebut dicari alternatif cara kerja yang paling tepat untuk mencapainya.(Gitosudarmo,Indriyo.1988. hal 27-28). Perencanaan produksi ini merupakan suatu fungsi yang menentukan batas-batas (level) dari kegiatan perusahaan di masa mendatang. Berdasarkan rencana-rencana produksi yang telah disusun, pimpinan perusahaan dapat menentukan langkah-langkah sebagai berikut : a. Bilamana kegiatan produksi dimulai dan berapa banyak buruh/ pekerja yang dibutuhkan dalam kegiatan produksi tersebut $b$. Menentukan alat-alat dan perlengkapan yang diperlukan dalam proses produksi ; c. Tingkat persediaan yang dibutuhkan.

Tujuan perencanaan produksi ini adalah :

1. Untuk mencapai tingkat/level keuntungan (profit) tertentu. Misalnya berapa hasil (output) yang diproduksi supaya dapat dicapai tingkat/level profit yang diinginkan dan tingkat persentase tertentu dari keuntungan (profit) setahun terhadap penjualan (sales) yang diinginkan.

2. Untuk menguasai pasar tertentu, sehingga hasil atau output perusahaan ini tetap mempunyai pangsa pasar (market share) tertentu.

3. Untuk mengusahakan supaya perusahaan ini dapat bekerja pada tingkat efisiensi tertentu.

4. Untuk mengusahakan dan mempertahankan supaya pekerjaan dan kesempatan kerja yang sudah ada tetap bersangkutan.

\section{Perencanaan Kapasitas}

Strategi operasi jangka panjang suatu organisasi sampai tingkat dinyatakan dalam rencana kapasitas. Dalam hubungannya dengan rencana kapasitaslah hal-hal berikut ini harus dipertimbangkan. Bagaimanakah kecenderungan pasarnya, baik dalam ukuran, lokasi pasar maupun inovasi teknologi, sejauh mana faktor-faktor ini dapat diperkirakan-diperkirakan, Apakah terlihat adanya inovasi teknologi di masa depan yang akan memebrikan dampak pada produk dan jasa,

Bagaimana pengaruh produk baru pada kebutuhan kapasitas. Apakah terlihat adanya inovasi dalam proses di masa depan yang akan mempengaruhi metode produksi, Apakah sistem produksi yang lebih kontinyu cocok di masa depan, Bagaimana kebutuhan kapasitas dipengaruhi oleh inovasi dalam proses produksi, Apakah akan menguntungkan untuk melakukan integrasi secara vertical selama jangka waktu perencanaan, dalam merencanakan kapasitas baru, apakah kita akan 
mengembangkan fasilitas yang suidah ada atau akan membangun pabrik baru, Berapakah ukuran pabrik yang optimal, Apakah serangkaian unit kecil ditambahkan apabila dibutuhkan, atau unit yang lebih besar ditambahkan secara periodik, Apakah kebijakannya adalah menyediakan kapasitas sedemikian hingga dimungkinkan adanya kehilangan penjualan dalam jumlah tertentu, ataukah seluruh permintaan harus dipenuhi.

Masalah-masalah strategis ini harus dipecahkan sebagai bagian perencanaan kapasitas. Dalam menilai alternatif-alternatif, maka pendapatan, biaya modal, dan biaya operasi dapat diperbandingkan, tetapi manajer mungkin harus menimbang akibat yang mungkin dari masalah strategis itu terhadap keuntungan dari kerugian ekonomis.

\section{Definisi Kapasitas}

Kapasitas adalah kemmapuan pembatas dari unit produksi untuk memproduksi dalam waktu tertentu, dan biasanya dinyatakan dalam bentuk keluaran (output) per satuan waktu, tetapi kapasitas adalah konsep, karena harus dihubungkan dengan sejauh mana suatu peralatan digunakan. Sebagai contoh, bisa saja ditetapkan sebagai kebijakan untuk bekerja hanya 5 hari seminggu, satu shift dalam sehari, dan produksinya 1.000 satuan per minggu.

Dengan dasar ini kita dapat mengatakan bahwa kapasitas normal adalah 1.000 satuan output per minggu. Tetapi batas ini dapat ditingkatkan dengan kerja lembur sehingga batas kapasitas dengan kerja lembur menjadi 1.150 satuan. Dengan menambah shift kedua, kapasitas dapat ditingkatkan lebih lanjut menjadi 1.800 satuan per minggu. Cara lain untukmeningkatkan batas kapasitas adalah dengan melakukan sub-kontrak apabila mungkin. Jadi, mengubah kebijakan mengenai pemanfaatan peralatan dapat mengubah kapasitas tanpa menambah peralatan. Sumber kapasitas ini dapat memberikan manajer keluwesan dalam menyusun perencanaan kapasitas.

\section{Ukuran Kapasitas}

Apabila satu output itu homogen, satuan kapasitasnya jelas. Misalnyasebagai satuan output pabrik mobil menggunakan jumlah mobil, pabrik bir menggunakan jumlah krat botol bir, dan pembangkit listrik tenaga nuklir menggunakan megawatt listrik.

Kalau satuan output itu berbeda-beda, biasanya digunakanlah ukuran pembatas pada kemampuan peralatannya sebagai ukuran kapasitas, sebagai contoh, perusahaan penerbangan menggunakan jumlah kursi-mil yang tersedia (jumlah kursi dikalikanb jarak penerbangan) sebagai ukuran kapasitas. Mereka tidak menggunakan "jumlah kursi" saja, karena ukuran seperti itu tidak memberikan petunjuk mengenai penggunaan kursi tersebut. Demikian juga, sebuah restoran tidak akan menggunakan jumlah kursi sebagai ukuran kapasitasnya, karena itu dapat digunakan. Jadi, ukuran yang tepat adalah berapa kursi dan berapa kali dapat melayani pembeli.(Buffa,Elwoods.1999 hal 121) Proses Perencanaan Kapasitas Proses dalam perencanaan kapasitas dapat diringkaskan sebagai berikut :

1. Memperkirakan permintaan di masa depan, termasuk dampak dari teknologi, persaingan dan lainnya.

2. Menjabarkan perkiraan itu dalam kebutuhan kapasitas fisik.

3. Menyusun piihan rencana kapasitas yang berhubungan dengan kebutuhan itu.

4. Menganalisis pengaruh ekonomi pada pilihan rencana.

5. Meninjau resiko dan pengaruh strategi pada pilihan rencana.

6. Memutuskan rencana pelaksanaan. (Buffa,Elwoods.1999.hal 122)

\section{Hierarki Perencanaan Prioritas dan Perencanaan Kapasitas dalam Sistem Manufacturing}

RoughCutcapacityPlanning (RCCP) merupakan urutan kedua dari hierarki perencanaan kapasitaskapasitas yang berperan dalam mengembangkan MPS.

Sebelum kita membahas lebih jauh tentang $R C C P$, perlu dikemukakan hierarki perencanaan prioritas (priority planning) dan perencanaan kapasitas (capacity planning). Untuk lebih jelasnya kita tampilkan kembali sistem MRP II. Pada dasarnya perencanaan manufacturing (manufacturing planning) mencakup perencanaan terhadap output daninput dari operasimanufacturing yang dikelompokkan dalam dua jenis perencanaan, yaitu : perencanaan prioritas (priority planning) yang berkaitan dengan perencanaan input.

Selanjutnya apabila dikaitkan secara langsung dengan perencanaan prioritas dan perencanaan kapasitas, hierarki dari sistem MRP II akan tampak seperti dalam gambar ini. 


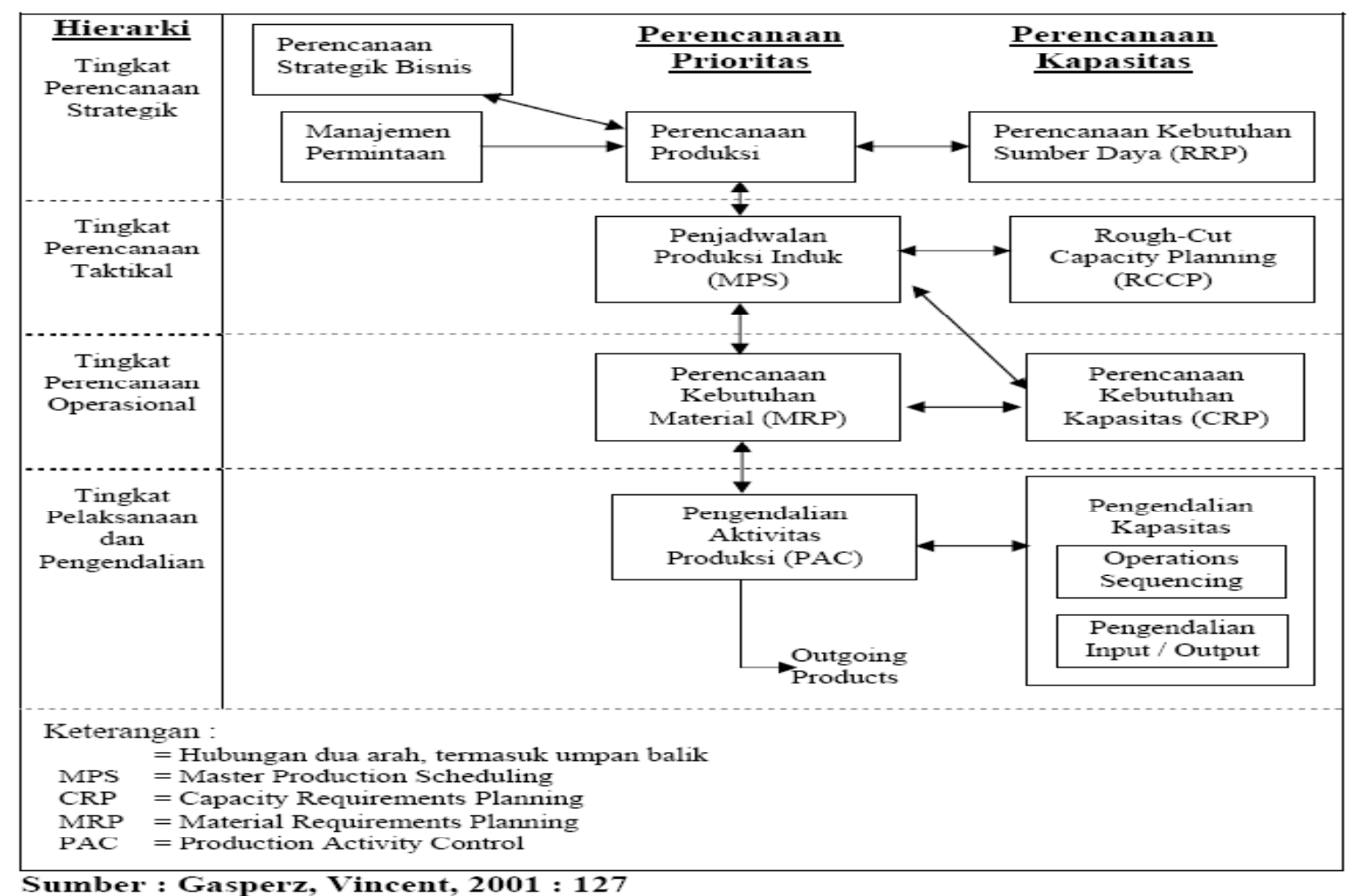

Gambar Hierarki perencanaan prioritas dan kapasitas dalam sistem MRP II

Dari Gambar tampak bahwa perencanaan produksi (production planning) dan perencanaan kebutuhan sumber daya (Resource Requirement Planning, RRP) termasuk dalam tingkat perencanaan strategik yang dilakukan oleh manajemen puncak (top management). Perencanaan produksi dan kebutuhan sumber daya berada pada level yang sama, dan merupakan level pertama dari hierarki perencanaan prioritas dan perencanaan kapasitas. Perencanaan kapasitas menentukan sumbersumber daya (input) atau tingkat kapasitas yang dibutuhkan oleh operasi manufacturing untuk memenuhi jadwal produksi atau output yang diinginkan, membandingkan kebutuhan produksi dengan kapasitas yang tersedia dan menyesuaikan tingkat kapasitas atau jadwal produksi perencanaan kapasitas mencakup kebutuhan sumber-sumberdaya manufacturing seperti : jam mesin, jam tenaga kerja, fasilitas peralatan, ruang untuk tempat penyimpanan (warehouse space), rekayasa (engineering), energi, dan sumber-sumber daya keuangan. Dalam sistem MRP II, perencanaan kapasitas tidak mencakup material, karena perencanaan material ditangani oleh fungsi perencanaan prioritas melalui penjadwalan produksi induk (Master Production $M P S)$ dan perencanaan kebutuhan material (Material Requirements Planning, MRP).
Keberhasilan perencanaan dan pengendalian manufacturing membutuhkan perencanaan kapasitas yang efektif, agar mampu memenuhi jadwal produksi yang ditetapkan. Kekurangan kapasitas akan menyebabkan kegagalan memenuhi target produksi, keterlambatan dan pengiriman ke pelanggan, dan kehilangan kepercayaan dalam sistem formal yang mengakibatkan reputasi dari perusahaan akan menurun atau hilang sama sekali. Pada sisi lain, kelebihan kapasitas akan mengakibatkan tingkat utilisasi sumber-sumber daya yang rendah, biaya meningkat, harga produk menjadi tidak kompetitif, kehilangan pangsa pasar, penurunan keuntungan dan lain-lain. Dengan demikian, kekurangan kapasitas maupun kelebihan kapasitas akan memberikan dampak negatif bagi sistem manufaktur, sehingga perencanaan kapasitas yang efektif adalah menyediakan kapasitas sesuai dengan kebutuhan pada waktu yang tepat. Sistem manufacturing tidak dapat memproduksi prioritas (output) yang diinginkan tanpa memiliki kapasitas (input) yang cukup. karena itu, dalam sistem manufacturing modern aktivitas perencanaan prioritas (priority planning) sejajar dengan aktivitas perencanaan kapasitas, sehingga terdapat suatu hierarki dari rencana-rencana kapasitas (capacity plants) yang sejajar dan sesuai dengan hierarki dari 
rencana-rencana prioritas (priority plans), seperti ditujukan dalam gambar di atas

\subsection{Rough Cut Capacity Planning (RCCP)}

Rough Cut Capacity Planning (RCCP) adalah suatu metode yang dipakai untuk menguji apakah perencanaan yang dituangkan dalam MPS fisibel atau tidak dibandingkan dengan kapasitas yang tersedia. $R C C P$ digunakan untuk menguji kelayakan kapasitas dari suatu rencana jadwal induk produksi (MPS) sebelum MPS ditetapkan. Prosedur ini dilakukan untuk memberi keyakinan bahwa MPS tidak melebihi kapasitas yang ada pada semua pusat kerja yang dapat menghambat kelancaran proses manufacturing. (Herjanto,Eddy.1999.hal.275)

Tujuan dari Rough Cut Capacity Planning (RCCP) adalah mengidentifikasi sumber daya untuk memenuhi jadwal induk produksi. Salah satu teknik RCCP adalah perencanaan kapasitas dengan menggunakan factor-faktor keseluruhan.

Pada dasarnya terdapat empat tingkat dalam hierarki perencanaan prioritas dan kapasitas yang terintegrasi, antara lain :

1. Perencanaan Produksi dan Perencanaan Kebutuhan Sumber Daya

2. Penjadwalan Produksi Induk (MPS) dan Rough Cut Capasity Planning (RCCP)

3. Perencanaan Kebutuhan Material (MRP) dan Perencanaan Kevbutuhan Kapasitas (CRP).

4. Pengendalian Aktivitas Produksi (PAC) dan pengendalian Input/Output serta Operasi Squencing.(Gasperz, Vincent.2001. hal. 125 128)

5. Rough Cut Capacity Planning (RCCP) menentukan apakah sumber daya yang direncanakanadalah cukup untuk melaksanakan MPS. RCCP menggunakan definisi (Product load profiles, bills of capacity, bills of resource, atau bill of labor). Penggandaan beban per unit dengan kuantitas produk yang dijadwalkan per

Perencanaan Kebutuhan Sumber Daya (RRP) dan RCCP

\begin{tabular}{|c|c|c|c|}
\hline No. & Deskaripsi & FRRP & $\mathbf{R C C P}$ \\
\hline $\mathbf{1}$ & Input & $\begin{array}{l}\text { Kelompok produle atau } \\
\text { item-item }\end{array}$ & $\begin{array}{l}\text { Produk-produk dan } \\
\text { komponen-komponen }\end{array}$ \\
\hline 2 & $\begin{array}{l}\text { Periode } \\
\text { Perencanaan }\end{array}$ & $\begin{array}{l}\text { - Trivulan atau } \\
\text { bulanan } \\
\text { - No offser }\end{array}$ & $\begin{array}{l}\text { - Mingguan atau harian } \\
\text { - Load time offset }\end{array}$ \\
\hline 3 & Output & Resource plan & Rough out capacity plan \\
\hline 4 & Metode & Bill of Resimce & Detailed product load profile \\
\hline
\end{tabular}

periode waktu akan memberikan beban total per periode waktu untuk setiap pusat kerja (work center).

6. $R C C P$ adalah lebih terperinci dari pada $R R P$, karena RCCP menghitung beban untuk semua item yang dijadwalkan dan dalam periode waktu actual.

Apabila proses $R C C P$ mengindikasikan bahwa $M P S$ adalah layak, $M P S$ akan diteruskan ke proses $M R P$ guna menentukan bahan baku atau material, komponen dan Sub assemblies, yang dibutuhkan. Dalam perusahaan yang berorientasi pada kapasitas seperti industri kimia, apabila $R C C P$ mengidentifikasikan ada masalah dengan MPS.

Perencanaan harus mengubah MPS melalui salah satu menjadwalkan ulang perasanan-pesaanan pelanggan (customer order) atau melalui pemberitahuan ke bagian pemasaran untuk tidak menjual melebihi kapasitas yang ada. (Gasperz, Vencent. 2001. hal 128-129) Pada dasarnya RCCP didefinisikan sebagai proses konversi dari rencana produksi dan/atau MPS ke dalam kebutuhan kapasitas yang berkaitan dengan sumber-sumber daya kritis, seperti: tenaga kerja, mesin dan peralatan, kapasitas gudang, kapabilitas pemasok, material dan parts, dan sumber daya. RCCP adalah serupa dengan Perencanaan Kebutuhan Sumber Daya (Resource Requirements Planning=RRP), kecuali bahwa

RCCP adalah lebih terperinci dari pada RRP dalam beberapa jal seperti: RCCP didisagregasikan ke dalam level item aatau SKU (Stock keeping Unit); RCCP didisagregasikan berdasarkan periode waktu harian atau mingguan; dan RCCP mempertimbangkan lebih banyak sumber dayaa produksi. beberapa perbedaan spesifik antara RRP dan RCCP dapat dilihat pada Tabel sebagai berikut. 
Pada dasarnya terdapat empat langkah yang diperklukan untuk melaksanakan RCCP, sebagai berikut :

1. Memperoleh informasi tentang rencana produksi dari MPS

2. Memperoleh informasi tentang struktur produk dan waktu tunggu (lead time)

3. Menentukan bill of resource

4. Menghitung kebutuhan sumber daya spesifik dan membuat laporan $R C C P$.(Garperz, Vincent. 2001. hal. 173)

\subsection{Konsep Dasar Tentang Aktivitas Penjadwalan Produksi Induk}

Sebelum memulai pembahasan tentang penjadwalan produksi induk (Master Production Scheduling=MPS) perlu dikemukakan kedua istilah tentang MPS, yaitu: (1) Penjadwalan produksi induk (master production scheduling=MPS), dan (2) Jadwal produksi induk (Master Production Scheduling=MPS). Pada dasarnya istilah MPS untuk jadwal produksi induk. (Master Production Scheduling $=$ MPS) merupakan hasil dari aktivitas penjadwalan produksi induk (Master Production Scheduling=MPS). Dengan demikian apabila ditemukan uraian yang berkaitan dengan aktivitas proses untuk menghasilkan MPS, yang dimaksudkan dengan $M P S$ di sini adalah jaadwal produksi induk (Master Production Scheduling=MPS). Sedangkan istilah MPS untuk penjadwalan produksi induk (master production scheduling $=M P S$ ) mengacu pada aktivitas proses untuk menghasilkan jadwal produksi itu.

Pada dasarnya jadwal produksi induk (Master Production Scheduling = MPS) merupakan suatu pernyataan tentang produk akhir (termasuk parts pengganti dan suku cadang) dari suatu perusahaan industri manufaktur yang merencanakan memproduksi output berkaitan dengan kuantitas dan periode waktu. MPS mendisagregasikan dan mengimplementasikan rencana produksi. apabila rencana produksi yang merupakan hasil dari proses perencanaan produksi (aktivitas pada level 1 dalam hierarki perencanaan prioritas) dinyatakan dalam bentuk agregat, jadwal produksi induk (Master Production Scheduling=MPS) yang merupakan hasil dari proses penjadwalan produksi induk (Master Production Scheduling=MPS) dinyatakan dalam konfigurasi spesifik dengan nomor-nomor item yang ada dalam item master dan BOM (Bills of Material) files. Aktivitas penjadwalan produksi induk (master production scheduling $=M P S$ or master scheduling) pada dasarnya berkaitan dengan bagaiaman menyusun dan memperbaharui jadwal produksi induk (Master Production Scheduling $=M P S$ ), memproses transaksi dari MPS, memelihara catatan-catatan MPS, mengevaluasi efektivitas dari MPS, dan memberikan laporan evaluasi dalam periode waktu yang teratur untuk keperluan umpan-balik dan tinjauan ulang.

Berdasarkan uraian di atas, kita mengetahui bahwa MPS berkaitan dengan pernyataan tentang produksi, dan bukan pernyataan tentang permintaan pasar. $M P S$ sering didefinisikan sebagai anticipate build schedule untuk item-item yang disusun oleh perencana jadwal produksi induk (master scheduling). MPS membentuk jalinan komunikasi antara bagian pemasaran dan bagian manufacturing, sehingga seyogyanya bagian pemasaran juga mengetahui informasi yang ada dalam MPS terutama berkaitan dengan ATP (Available To Promise) agar dapat memberikan janji yang akurat kepada pelanggan. Jangan sampai di era globalisasi yang menuntut profesionlisme tinggi, apabila ada pertanyaan dari pelangga tentang: "Apakah pesanan saya bisa dikirim pada tanggal 15 April (tahun tertentu)?" lalu masih dijumpai jawaban dari orang-orang di bagian pemasaran berupa : "Wah, saya tidak bisa menentukan karena semuanya tergantung pada bagian produksi di pabrik, mereka yang menyusun jadwal, apalagi pesanan lagi banyak dan menumpuk, serta kapasitas produksi kami terbatas!" Jawaban seperti ini menunjukkan bahwa industri manufaktur itu dikelola oleh orang-orang yang tidak profesional, karena tidak ada penerapan sistem manajemen manufaktur dalam industri itu. (Gasperz,Vincent.2001.hal 141-142)

Sebagai suatu aktivitas proses, penjadwalan produksi induk (MPS) membutuhkan lima input utama seperti dalam Gambar 


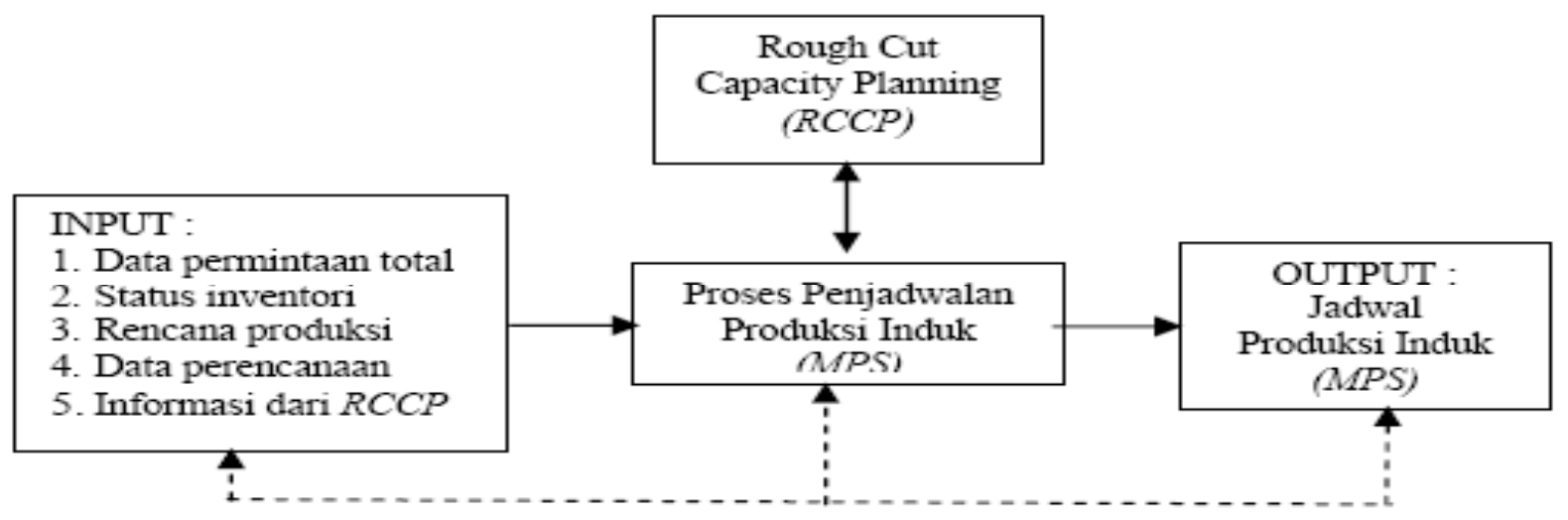

Umpan Balik

Gambar Proses Penjadwalan Produksi Induk Sumber : Gasperz, Vincent. 2001 : 143

Data permintaan total merupakan salah satu sumber data bagi proses penjadwalan produksi induk. Data permintaan total berkaitan dengan ramalan penjualan (sales forecasts) dan pesananpesanan (orders). Status inventori berkaitan dengan informasi tentang on-hand inventory, stok yang dialokasikan untuk penggunaan tertentu (allocated stock), pesanan-pesanan produksi dan pembelian yang dikeluarkan (released production and purchase orders) dan firm planned orders. MPS harus mengetahui secara akurat berapa banyak inventori yang tersedia dan menentukan berapa banyak yang harus dipesan. Rencana produksi memberikan sekumpulan batasan kepadaMPS.MPS harus menjumlahkannya untuk menentukan tingkat produksi, inventori dan sumber-sumber daya lain dalam rencana produksi itu. Data perencanaan berkaitan dengan aturan-aturan tentang lot-sizing yang harus digunakan, sbrimkage factor, stok pengaman (safety stock) dan waktu tunggu (lead time) dari masing-masing item yang biasanya tersedia dalam file induk dari item (Item Master File). Informasi dari RCCP berupa kebutuhan kapasitas untuk mengimpelementasikan MPS menjadi salah satu input bagi MPS. Pada dasarnya RCCP dan MPS merupakan aktivitas perencanaan yang berada pada level yang sama (level 2) dalam hierarki perencanaan prioritas dan perencanaan kapasitas pada sistem MRP II. RCCP menentukan kebutuhan kapasitas untuk mengimplementasikan MPS, menguji kelayakan jadwal produksi induk (master scheduler) untuk mengambil tindakan perbaikan apabila ditemukan adanya ketidaksesuaian aantara penjadwalan produksi induk dan kapasitas yang tersedia. Seperti telah dikemukakan dalam sistem MRP II, penjadwalan produksi induk (Master Production Scheduling=MPS) merupakan aktivitas perencanaan yang berada pada level 2 dalam hierarki perencanaan prioritas, sedangkan perencanaan yang berada pada level 1 (level yang lebih tinggi) dakam hierarki perencanaan prioritas. Pada dasarnya terdapat sejumlah perbedaan antara rencana produksi (production plan) dan jadwal produksi induk (Master Production Scheduling=MPS) yang merupakan hasil dari kedua aktivitas perencanaan tersebut

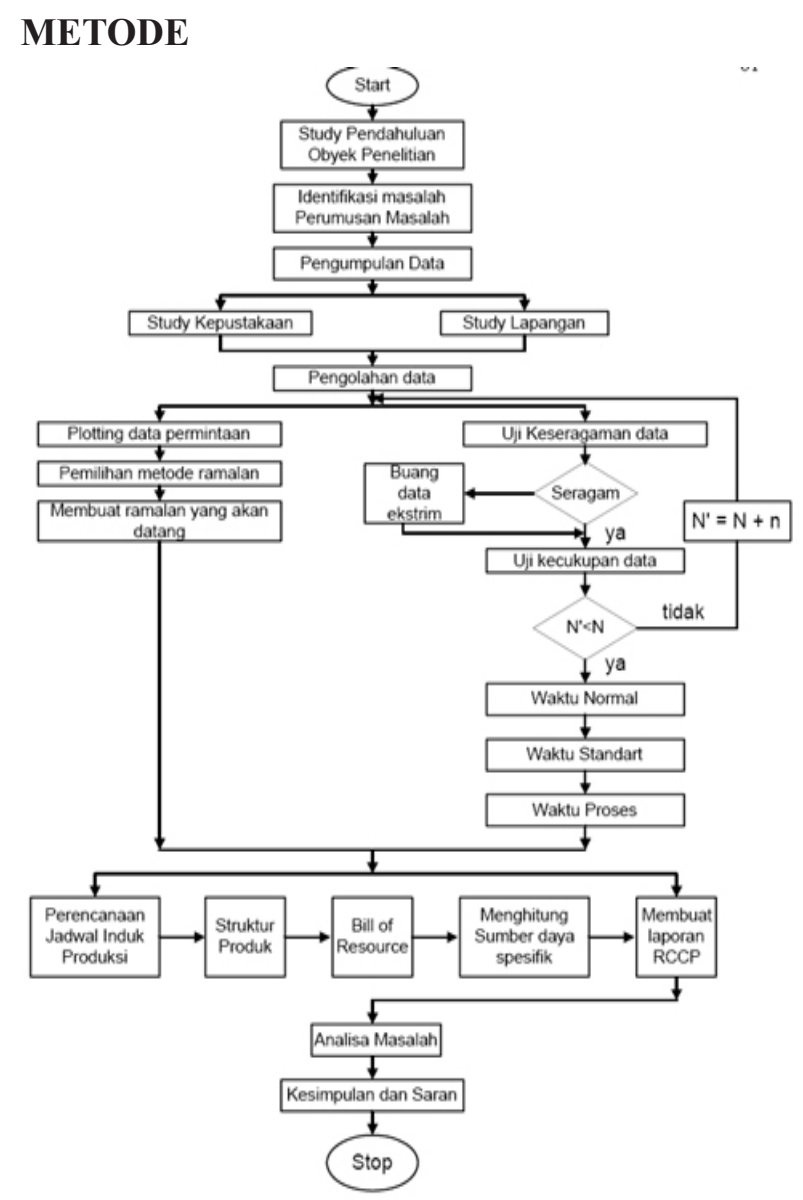

Gambar Flow- Chart Metode Penelitian 


\section{HASIL DAN PEMBAHASAN}

Setelah melakukan pengolahan dan analisa data, maka penulis dapat mengambil kesimpulan sebagai berikut: Dari perhitungan dapat diketahui jenis peramalan yang digunakan adalah metode Single Exponensial Smoothing.Nilai MAD nya sebesar 102044,3. dibandingkan dengan Double Exponensial Smoothing.Nilai MAD nya sebesar 102852,4 atau dengan Weighted Moving Avarages Model yang nilai MAD nya sebesar 90099,63. Dari hasil peramalan terhadap jumlah permintaan periode sebelumnya dengan 12 periode kita dapat membuat jadwal induk produksi dan menyusun Bill Of Resoursce dengan jam standart yaitu 0,000316 $\mathrm{jam} / \mathrm{kg}$. Dapat mengetahui kebutuhan kapasitas mesin dengan 1 hari kerja $=8$ jam kerja, dengan 3 shift per hari, 1 minggu $=6$ hari kerja , 1 bulan $=25$ hari kerja efektif maka:

Waktu tersedia per bulan $=25$ hari kerja efektif $\times 8$ jam kerja $\times 3$ shift per hari $=600$ jam/bulan

Kapasitas yang tersedia untuk mesin Washing $=3$ x $600 \times 0,88 \times 0,88=1.394 \mathrm{jam} / \mathrm{bulan}$

Kapasitas yang t ersedia untuk mesin Crushing $=3$ x $600 \times 0,88 \times 0,88=1.394 \mathrm{jam} /$ bulan Kapasitas yang tersedia untuk mesin Pelletizing $=$ $4 \times 600 \times 0,88 \times 0,88=1.859 \mathrm{jam} / \mathrm{bulan}$

\section{Dapat mengetahui Capacity Load Profile} masing-masing mesin

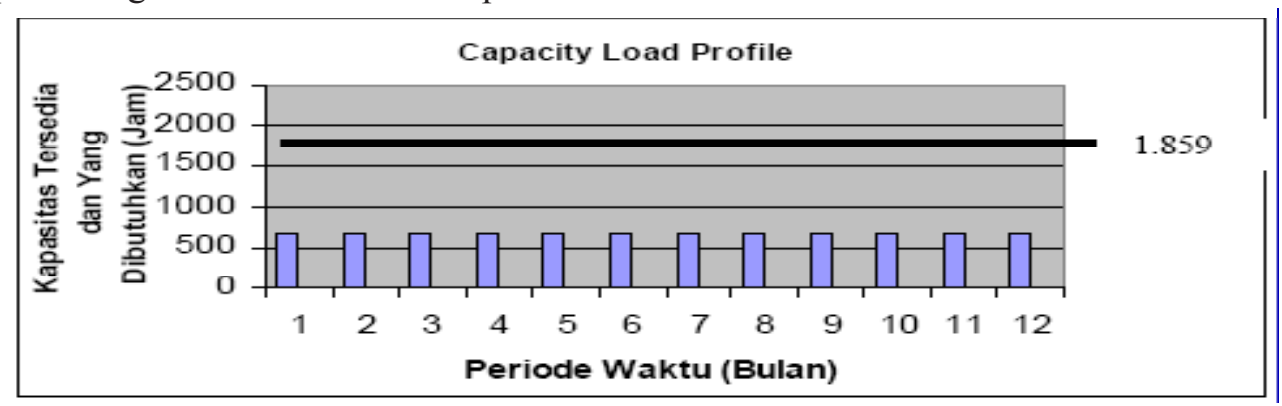

Gambar Capacity Load Profile Mesin Washing

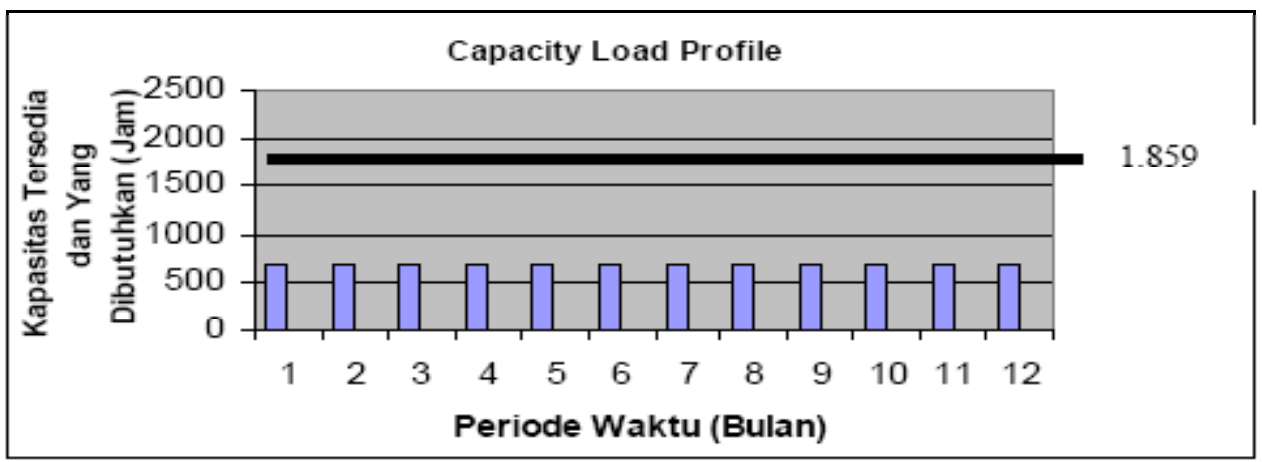

Gambar Capacity Load Profile Mesin Crushing

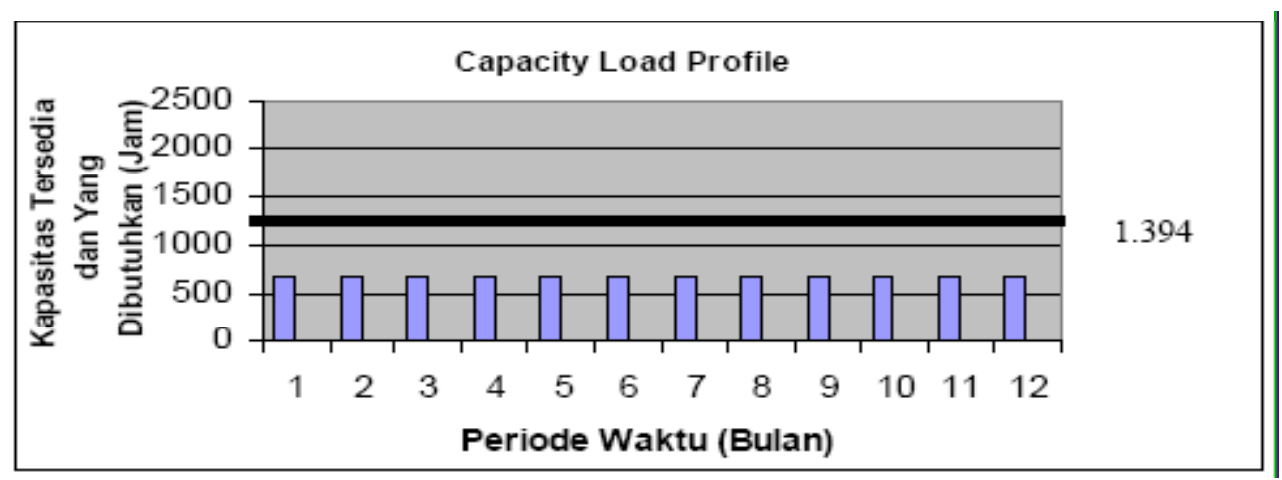

Gambar Capacity Load Profile Mesin Pelletizing 
Keterangan: - Kapasitas Tersedia ; - Kapasitas Yang Dibutuhkan

Dari gambar diatas kebutuhan actual lebih kecil dari pada kapasitas yang tersedia dan jadwal induk produksi layak/dapat dipergunakan pada perusahaan.

\section{KESIMPULAN}

Perusahaan dapat memproduksi produk Pellet Polyprophylen lebih banyak lagi karena kapasitas mesin yang tersedia masih cukup dari kapasitas yang dibutuhkan. Perusahaan dapat merencanakan kembali jadwal induk produksi, agar dapat menjadwalkan pesanan-pesanan produksi.

\section{DAFTAR PUSTAKA}

Alhusin, Syahri, Aplikasi Statistik Praktis dengan Menggunakan SPSS 10 for Windows, edidsi kedua, Yogyakarta; Penerbit Graha IImu, 2003

Assauri, Sofyan. Manajemen Produksi dan Operasi. Jakarta. Fakultas Ekonomi Universitas Indonesia. 1999

Basu Swasata, 1997, “Analisa Perilaku Konsumen Dalam Upaya Penyusunan Strategi Pemasaran Yang Tepat Dan Efektif ”, Edisi Kedua, Penerbit Gramedia Jakarta

Buffa, 1995, Managemen Produksi / Operasi, Penerbit Erlangga, Jakarta.

Chapnish, A. 1983, Introduction to Human Factor Consideration in System Design, In C.M. Mitchel, P. Van Balen and K. Moe Leas, Nasa Conference Publ. 2246, Washington.

Bambang Tri Cahyono , 1996, “ Manajemen Pemasaran "IPWI Jakarta

Gasperz, Vincent. Produktion Planning And Inventory Control. Jakarta. Gramedia Pustaka Utama 2001

Gitosudarmo, Indriyo. Sistem Perencanaan dan Pengendalian Produksi Yogyakarta. BPFE. 1988

Husnan, S. dan Muhammad, S., 1984, Studi Kelayakan Proyek, BPFE, Yogyakarta.

Hendra Kusuma, 2004, Manajemen Produksi Perencanaan dan Pengendalian Produksi, edisi ketiga, Penerbit ANDI, Yogjakarta.

Herjanto, Eddy. Manajemen Produksi dan Operasi. Jakarta. Binarupa Aksara. 1999

Nasution, H Arman. Perencanaan dan Pengendalian Produksi. Jakarta. Ganesa widya 1999

Iman Soeharto, 1997, Manajemen Proyek Dari
Konseptual Sampai Operasional, Erlangga, Jakart.

Kotler, Philips, 1987 , “ Dasar Dasar Pemasaran “, Edisis Tiga, Jilid Satu, Penerbit Intermeddia Jakarta

Masri Singarimbun dan Sofian Effendi, Metode Penelitian Survai, jakarta, 1989.

Niti Semito , 1984,” Marketing “, Edisi Kelima , Penerbit Yudistira

Nasution, Arman H, 1995, Perancangan \& Pengendalian persedian, Departemen Teknik Industri, ITS, Surabaya.

Sofyan Assauri, 1993, Manajemen Produksi, Lembaga PenerbitFakultas Ekonomi Universitas Indonesia.

Siagian P., 1987, Penelitian Operasional : Teori dan Praktek, UI-Press, jakarta

Sciffman, Leon G. , Leslie L. Kanuk, Consumer Behavior. Prentice Hall Inc. , Englewood Cliffs, fourth edition, 1981, New Jersy

Singgih aSntoso ,2002, SPSS,"Statistic Multivariate " Edisi Pertama, Penerbit PT. Gramedia Jakarata

Santoso. Budi, 1997, Manajemen Proyek, Edisi Ketiga, Gubna Widya, Jakarta Suta Laksana, Iftikar Z. Teknik Tata Cara Kerja. Bandung. ITB. 1979

T. Ali Haedar, 1986, Prinsip-Prinsip Network Planning, PT. Gramedia, Jakarta.

Teguh Baroto, 2002, Perencanaan dan Pengendalian Produksi, Penerbit Ghalia Indonesia.

T. Hani Handoko, 1994, Manajemen, Edisi Kedua, BPFE, Yogyakarta

Tjutju Tarliah Dimyati, Akhmad Dimyati, 1994 ; Operations Research, Model-model Pengambilan Keputusan, penerbit PT. Sinar Baru Algensindo Bandung

Wignjosoebroto, Sritomo, 1992, Teknik Tata Cara dan Pengukuran Kerja, edisi kedua, ITS, Surabaya. 